\title{
EFFECT OF CAST RECTIFIERS ON THE MARGINAL FIT OF UCLA ABUTMENTS
}

\author{
Ana Paula Gumieiro JAIME${ }^{1}$, Diego Klee de VASCONCELLOS ${ }^{2}$, Alfredo Mikail Melo MESQUITA ${ }^{3}$, \\ Estevão Tomomitsu KIMPARA ${ }^{4}$, Marco Antonio BOTTINO ${ }^{4}$
}

\begin{abstract}
1- DDS, Undergraduate student, Department of Dental Materials and Prosthodontics, Dental School of São José dos Campos, São Paulo State University "Júlio de Mesquita Filho", São José dos Campos, SP, Brazil.

2- DDS, MSc, PhD, Graduate student, Department of Dental Materials and Prosthodontics, Dental School of São José dos Campos, São Paulo State University "Júlio de Mesquita Filho", São José dos Campos, SP, Brazil.

3- DDS, MSc, Graduate student, Department of Dental Materials and Prosthodontics, Dental School of São José dos Campos, São Paulo State University "Júlio de Mesquita Filho", São José dos Campos, SP, Brazil.

4- DDS, MSc, PhD, Associate Professor, Department of Dental Materials and Prosthodontics, Dental School of São José dos Campos, São Paulo State University "Júlio de Mesquita Filho”, São José dos Campos, SP, Brazil.

Corresponding address: Alfredo Mikail Melo Mesquita - Rua: Baturité, 54 apto. 11 - Aclimação - São Paulo - SP - 01530-030 e-mail: alfmikail@yahoo.com.br
\end{abstract}

Received: April 27, 2006 - Accepted: May 18, 2007

\begin{abstract}
bjectives: This study assessed the effect of cast rectifiers on the marginal misfit of cast UCLA abutments compared to premachined UCLA abutments. The influence of casting and porcelain baking on the marginal misfit of these components was also investigated. Methods: Two groups were analyzed: test group - 10 cast UCLA abutments, finished with cast rectifier and submitted to ceramic application; control group - 10 premachined UCLA abutments, cast with noble metal alloy and submitted to ceramic application. Vertical misfit measurements were performed under light microscopy. In the test group, measurements were performed before and after the use of cast rectifiers, and after ceramic application. In the control group, measurements were performed before and after casting, and after ceramic application. Data were submitted to statistical analysis by ANOVA and Tukey's test $(\alpha=5 \%)$. Results: The use of cast rectifiers significantly reduced the marginal misfit of cast UCLA abutments (from $25.68 \mu \mathrm{m}$ to $14.83 \mu \mathrm{m} ; \mathrm{p}<0.05)$. After ceramic application, the rectified cylinders presented misfit values $(16.18 \mu \mathrm{m})$ similar to those of premachined components $(14.3 \mu \mathrm{m})$. Casting of the premachined UCLA abutments altered the marginal misfit of these components (from $9.63 \mu \mathrm{m}$ to $14.6 \mu \mathrm{m}$; $\mathrm{p}<0.05$ ). There were no significant changes after porcelain baking, in both groups. Conclusion: The use of cast rectifiers reduced the vertical misfit of cast UCLA abutments. Even with carefully performed laboratory steps, changes at the implant interface of premachined UCLA abutments occurred. Ceramic application did not alter the marginal misfit values of UCLA abutments.
\end{abstract}

Uniterms: Dental abutments; Misfit.

\section{INTRODUCTION}

Osseointegration offers new treatment options for the edentulous and partially edentulous patient. The use of dental implants to support and retain dental prostheses has been demonstrated to be clinically efficacious.

A precise fit between an implant abutment and a superstructure, determining the absence of bone tension, without the occlusal load, is an important factor for the longterm success of implant-supported restorations. Considering the fact that implants are completely surrounded by bone, and that the interface is not elastic, a minimum movement is observed due to bone deformation under loading. Accordingly, it must be anticipated that stress introduced into the implant system as the result of prosthesis misfit may be present many years after placement because of the ankylotic nature of the osseointegration. The present findings support the concern for precision of frameworks with regard to various aspects of fatigue in the long-term perspective ${ }^{2,13}$.

A widely used solution in implant-anchored prosthesis is the castable plastic patterns (UCLA abutment). This abutment is designed to directly engage the implant and thus allows the prosthodontist extending the porcelain subgingivally in areas with extremely limited gingival tissue height. The subgingival placement of the restoration not only improves esthetics but also helps in situations with interocclusal distance limitations ${ }^{20}$. The use of such abutments allows correction in angulations for implants inserted at angles other than ideal. For single-tooth 
restorations, the provision of an antirotational device is necessary; for fixed partial restorations, non-hexed castable UCLA abutments present as a better alternative.

There has been concern as to whether the use of these custom-made abutments would result in fit of the abutment to the implant that could be comparable to that achieved with use of premachined titanium abutments. An intermediate solution was developed, whereby premachined UCLA abutments made of noble metal alloys could be cast onto directly to allow integration of the restoration with the abutment. Another alternative is the use of cast rectifiers. These hand-operated devices have been developed to correct casting defects in the fitting surface and reduce the abutment/implant misfit.

Despite various prosthetic and technical improvements, laboratory procedures used in the fabrication of implantsupported prostheses, especially casting and porcelain baking, may alter the abutment surfaces in contact with the implant ${ }^{4,5,19,21}$.

This study evaluated the effect of cast rectifiers on the misfit of cast UCLA abutments compared to premachined UCLA abutments. The influence of casting and porcelain baking on the marginal misfit of these components was also investigated.

\section{MATERIALAND METHODS}

Two groups of components were analyzed: test group $(n=10)$ - castable plastic non-hexed UCLA abutments (055021;Conexão Sistemas de Prótese; São Paulo, SP, Brazil); control group $(n=10)$-non-hexed premachined UCLA abutments (055022; Conexão Sistemas de Prótese, São Paulo, SP, Brazil) (Figure 1A).

The components of both groups were individually positioned over an implant analogue (013020; Conexão Sistema de Próteses, São Paulo, SP, Brazil) and sectioned with a diamond bur (34570; Microdont, São Paulo, SP, Brazil) at low speed under water cooling until they were $8 \mathrm{~mm}$ in height, keeping the cylindrical shape.

The abutments were secured to the sprues and fixated in a sprue former. A silicone-casting ring was adapted to the sprue former and the investment was poured (Bellavest T; Bego, Bremen, Germany). Four silicone rings were used, each one containing 5 UCLA abutments, adding up to 20 components (10 per group).

The patterns were induction cast: abutments of the test group with a nickel-chromium alloy (Wiron 99; Bego, Bremen, Germany), and abutments of the control group with a palladium-silver alloy (Williams W1; Ivoclar Vivadent, Amherst, NY, USA). Castings were allowed bench cool and were then divested and cleaned with air abrasion. During this process, implant analogues were joined to the abutments to reduce the risk of damage to the abutment/implant interface (Figure 1B).

Fitting surfaces of the castings made with plastic patterns (test group) were milled with the cast rectifiers (Conexão Sistema de Próteses, São Paulo, SP, Brazil), by turning the tool against the abutment fitting surface twenty times in a clockwise direction. A new rectifying tool was used for every 5 components. A single operator performed this procedure (Figures 2 and 3)

In all 20 specimens, porcelain (Omega 900; Vita, Bad Säckingen, Germany) was applied to the abutments, carved

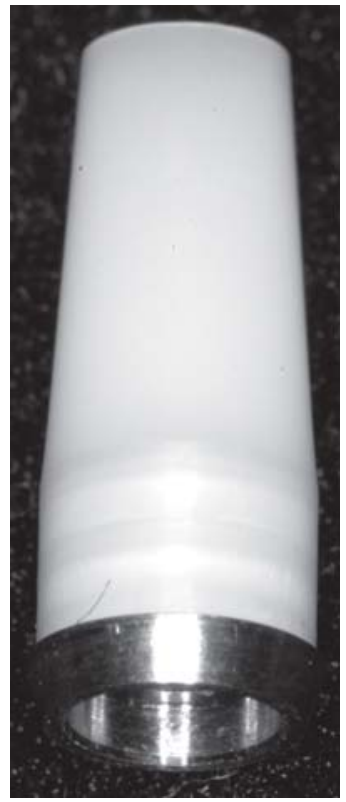

A

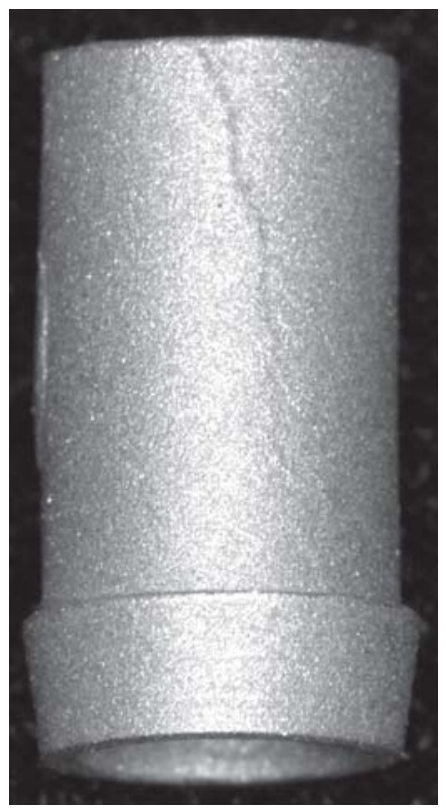

B
FIGURE 1 A- Gold Ucla / B- Cast Ucla in NiCr

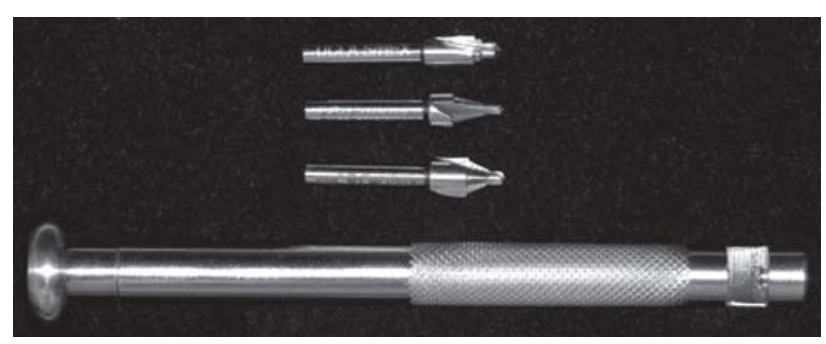

FIGURE 2- Cast Rectifiers

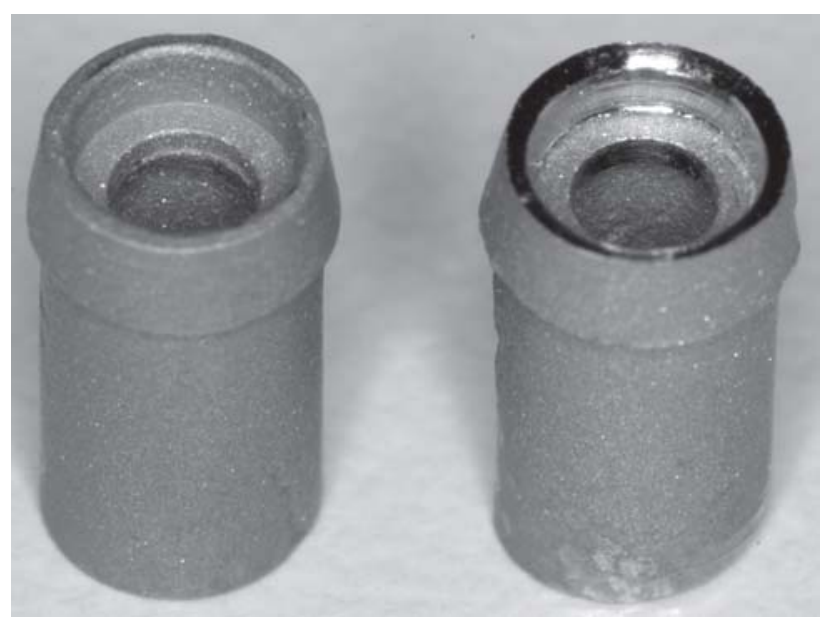

FIGURE 3- Cast abutments before and after the use of rectifiers 
and then baked according to the manufacturer's recommendations. Porcelain addition was standardized with a Teflon cylindrical device perfectly fitted to the implant analogue, which had adequate space for the application of the same bulk of material (nearly $1.5 \mathrm{~mm}$ ) in all specimens.

Misfit measurements were performed with a light microscope (Sprint 100; RAM Optical Instrumentation, Irvine, CA, USA). A standard threaded 3.75X13-mm implant (517713 Screw; Conexão Sistemas de Prótese, São Paulo, SP, Brazil) was stabilized in the center of a brass support, machined to achieve a final hexagonal configuration, allowing lateral seating on the light microscope (Figures 4A-B and 5).

Laser marks were created in the abutments and in the implant to allow positioning of the components at the same place during microscopic measurements. The abutments were attached to the implants in the predetermined position and screw was tightened to a torque of $5 \mathrm{Ncm}$, with a torque driver (Figure 6).

Three microscopic measurements at X460 magnification were made for each aspect of the hexagonal base, at reading points predetermined by laser marks on the lateral aspect of the implant platform, adding up to 18 reading points for each specimen. The measurements were recorded in micrometers $(\mu \mathrm{m})$

Marginal misfit measurements in the test group were performed before (M1) and after (M2) the use of rectifiers, and after ceramic application (M3). In the control group, measurements were performed before (M1) and after (M2) casting, and after ceramic application (M3) (Figure 7).

Data were submitted to statistical analysis by analysis of variance. Individual comparisons were done by Tukey's post-hoc test. Significance level was set at 5\%.

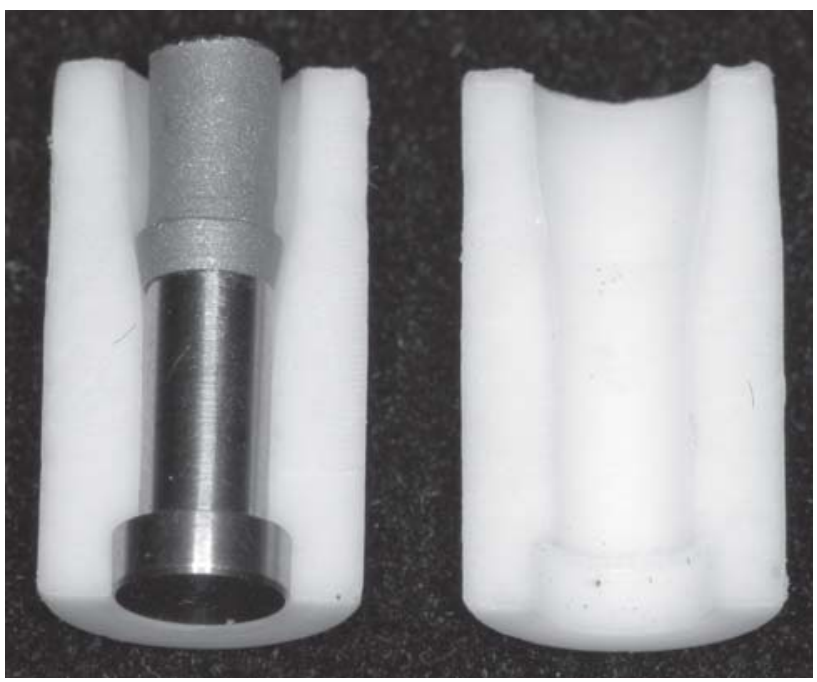

A

\section{RESULTS}

Means and standard deviations of marginal misfit (in $\mu \mathrm{m}$ ) for both groups at the 3 test moments (M1, M2, M3) are presented in Table 1.

The cast UCLA abutments (test group - M1) showed the greatest discrepancies, with marginal misfit mean of 25.68 $\mu \mathrm{m}$. Premachined UCLA abutments exhibited discrepancies

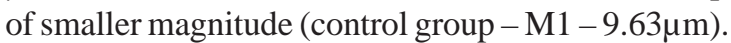

With the use of abutment rectifiers (test group - M2),

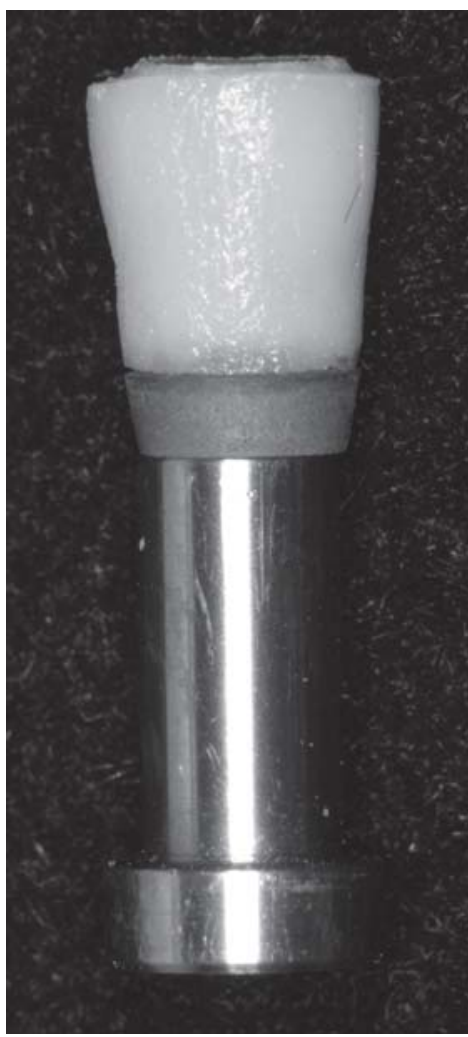

FIGURE 5- Porcelain applied to the abutments

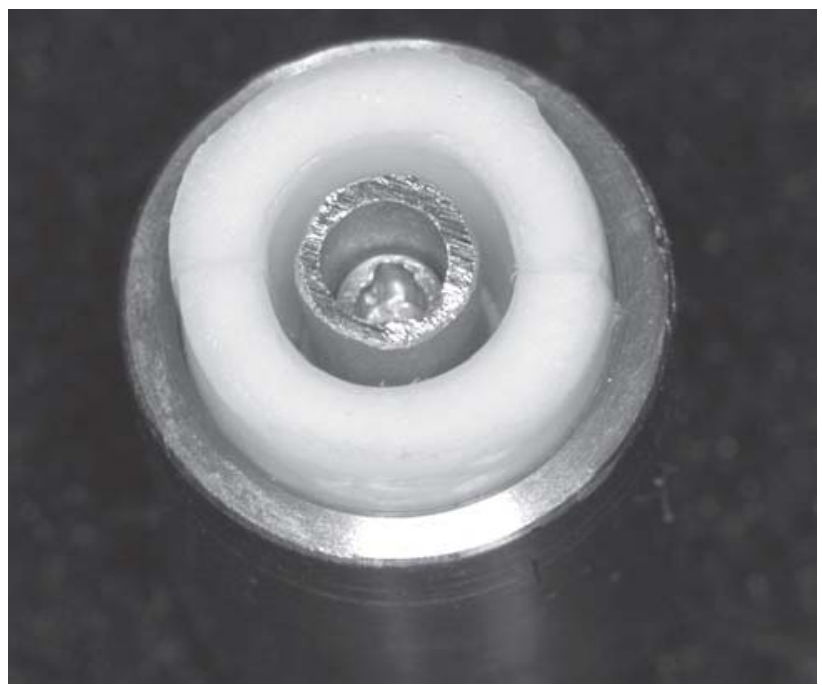

B

FIGURE 4 A and B-Teflon cylindrical device for the standardized porcelain application 
there was significant reduction of the marginal misfit of cast UCLA abutments, from $25.68 \mu \mathrm{m}$ to $14.83 \mu \mathrm{m}$. After ceramic application (M3), the cast abutments presented marginal

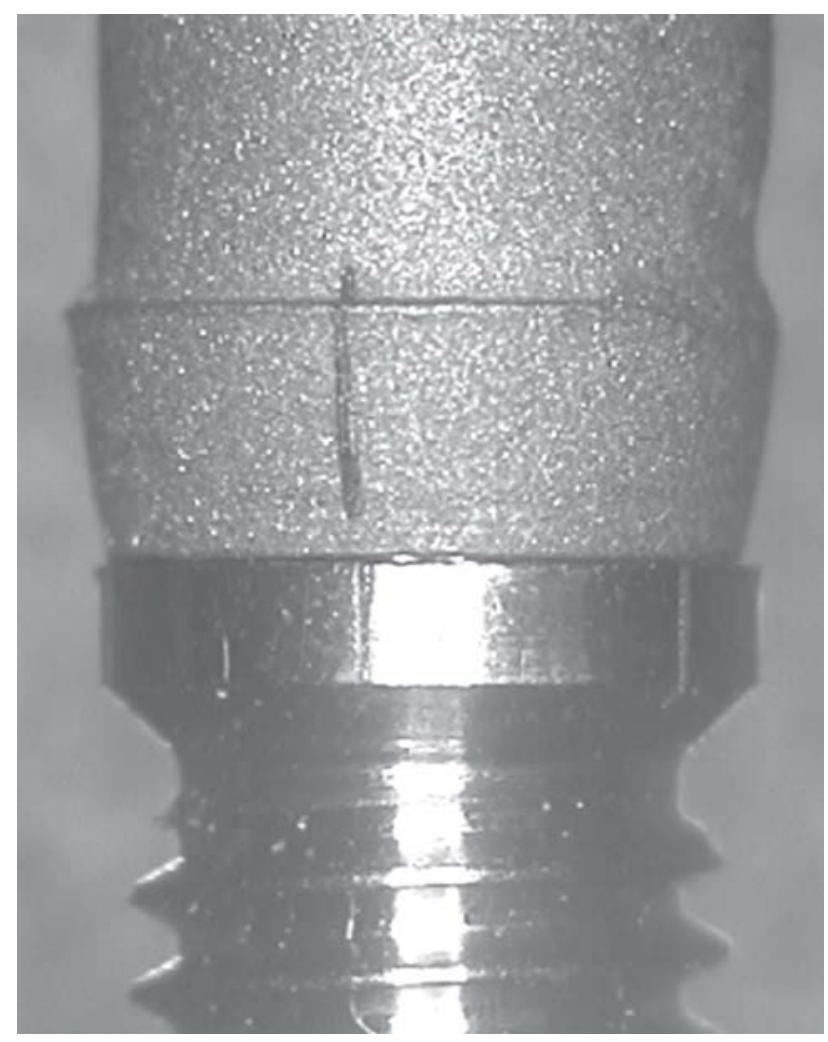

FIGURE 6-Cast Abutment on implant

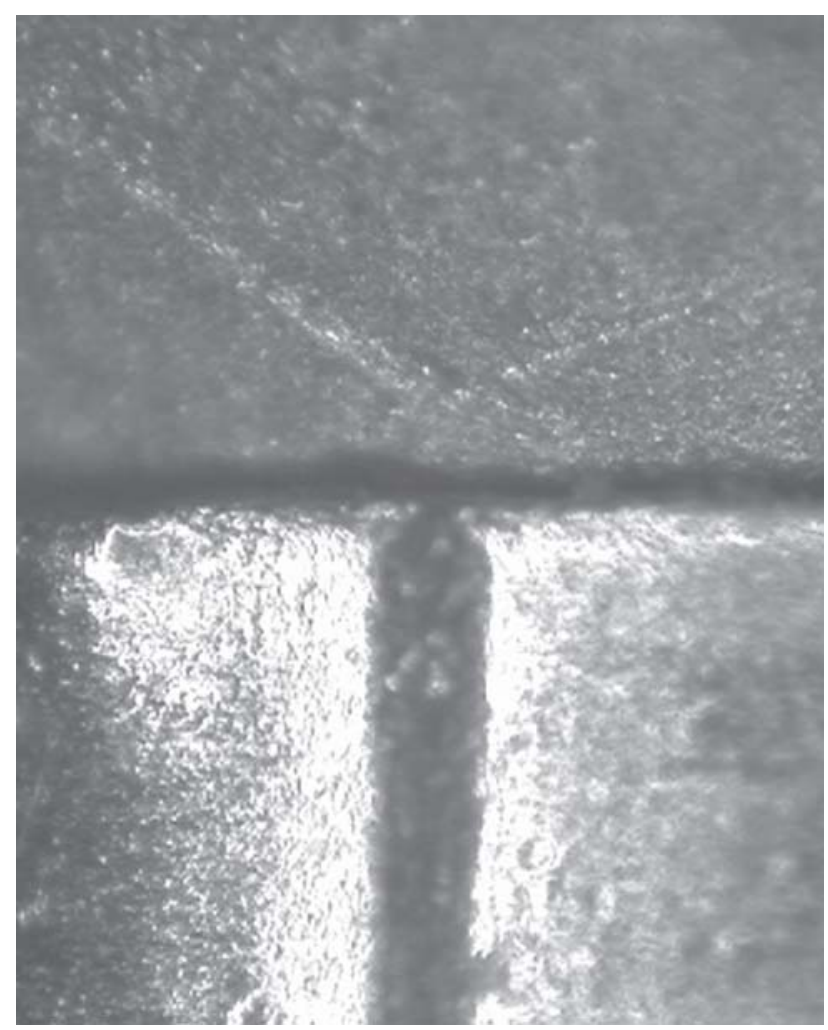

FIGURE 7- Laser marks created in the abutments and in the implant misfit mean $(16.18 \mu \mathrm{m})$ statistically similar to that observed for the premachined abutments at the same interval (14.3 ìm).

Casting of the premachined UCLA abutments (control group - M2) altered significantly the marginal misfit of these components (from 9.63 ìm to $14.6 \mu \mathrm{m}$ ). There were no significant changes due to the porcelain baking, in both groups investigated.

\section{DISCUSSION}

Several studies have demonstrated the success of Implantology ${ }^{9,18}$. However, despite the evolution of this specialty, clinical complications are still frequent. Numerous studies have been conducted to understand and reduce occasional complications ${ }^{11,16}$. In spite of the advances in technology, the materials and techniques employed in the fabrication of prosthetic structures are not dimensionally accurate and require further investigation and development. Distortions of such structures are inevitable and it is impossible to achieve a perfect fit and absolute passivity at the prosthetic interfaces ${ }^{8,17}$. Prosthesis misfit favors bacterial colonization, leading to inflammation of the periimplant soft tissues and harming osseointegration ${ }^{3,11}$. This lack of precision also contributes to an unfavorable distribution of stresses, which may lead to mechanical complications, such as the loosening or fracture of the screws and prosthetic components, in addition to biological complications, such as periimplant bone loss and impairment of osseointegration in more severe cases ${ }^{6,11,17}$.

Prosthetic protocols employing machined components reduce these risks, due to the higher accuracy of fit $^{19}$. However, to allow more versatility in overcoming angulation and esthetic problems, castable plastic patterns (UCLA abutments) permit esthetic restorations to be finished very close to the implant head, solving many esthetic dilemmas.

The use of this prosthetic option has increased even though the fit at the abutment to implant interface is not as satisfactory as the fit provided by premachined abutments ${ }^{3,19}$. Due to this increased search for components,

TABLE1- Means and standard deviations (SD) of the marginal misfit (micrometers) for both groups at the three test moments (M1, M2, M3)

\begin{tabular}{llll}
\hline Group & $\mathbf{n}$ & Mean & SD \\
\hline Gold UCLA M1 & 10 & $9.63 \mathrm{a}$ & \pm 0.67 \\
Gold UCLA M2 & 10 & $14.6 \mathrm{~b}$ & \pm 3.02 \\
Gold UCLA M3 & 10 & $14.3 \mathrm{~b}$ & \pm 1.71 \\
Nickel-chromium M1 & 10 & $25.68 \mathrm{c}$ & \pm 5.5 \\
Nickel-chromium M2 & 10 & $14.83 \mathrm{~b}$ & \pm 2.88 \\
Nickel-chromium M3 & 10 & $16.18 \mathrm{~b}$ & \pm 3.36 \\
\hline
\end{tabular}

Means followed by the same letters are statistically similar at $5 \%$ significance level (Tukey's test). 
companies have developed alternatives to reduce misfit, such as the premachined UCLA abutments. Other option is the use of castable plastic patterns followed by a laboratory finishing of the fitting surface with a cast rectifier. This device is a manual instrument designed to minimize the marginal misfit of cast UCLA abutments, leading to a better mechanical stability of the assembly and reducing the probability of bacterial aggregation.

There is a limitation for the use of cast UCLA rectifiers. This hand-operated device has been developed only for non-hexed cast UCLA abutments (i.e., without the antirotational device). Therefore, it cannot be used for hexed UCLA abutments (single-tooth restorations).

The present study revealed high values of marginal misfit in the castings made with plastic patterns (test group M1 $25.68 \mu \mathrm{m})$ compared to premachined abutments $(9.63 \mu \mathrm{m})$. Similar results were described by Byrne, et al. ${ }^{3}$ (1998). The factors that contribute to the distortion of castings, directly impairing the marginal fit between components, include fabrication of acrylic cylinders, limitations of investment processes and casting techniques. The use of cast rectifiers led to a significant reduction of marginal misfit of cast UCLA abutments, with a reduction of marginal misfit means from $25.68 \mu \mathrm{m}$ to $14.83 \mu \mathrm{m}$. The reduction of vertical misfit reduces the mechanical instability of prosthetic components, thereby eliminating the gaps for bacterial colonization.

Concerning the premachined abutments used as a reference, the mean marginal misfit after the ceramic application (M3) was $14.3 \mu \mathrm{m}$. The cast abutments used in the present study, after the use of rectifiers and porcelain baking (M3), exhibited a mean marginal misfit of $16.18 \mu \mathrm{m}$, which was statistically equivalent to the mean observed for premachined components at the same interval (14.3 $\mu \mathrm{m})$.

In disagreement with the findings of Vigolo, et al. ${ }^{20}$ (2000), the present investigation demonstrated that, for the group of premachined abutments, even with the carefully conducted laboratory steps, significant changes occurred at the implant/abutment interface during the casting process, with an increase in the mean marginal gap from 9.63 to 14.6 ìm.

Ceramic application did not change the marginal misfit in any the groups. These results are in agreement with the findings of previous studies ${ }^{1,3,4,7}$, which did not find significant dimensional alteration of the metal secondary to the ceramic application.

The seating force used to place the samples on the master cast has an important effect on the vertical misfit. The use of a torque driver, even with the lowest torque available (10 $\mathrm{N} / \mathrm{cm}$ ), may considerably narrow the vertical misfit gaps at the abutment-framework interface ${ }^{9,12,21}$. Marginal misfit investigations, in which screws are hand fastened, always by the same investigator, until the first resistance is met, as suggested Zervas, et al. ${ }^{21}$ (1999), allows a more real fit evaluation because no attempt is made to narrow the vertical misfit gaps. However, it seems to be a risky protocol, due to the wide variation in the ability of the clinicians to perceive torque, making difficult the standardization of the screw tightening procedure prior to microscope measurements. In the present study, a special torque driver was fabricated, reducing the torque to $5 \mathrm{~N} / \mathrm{cm}$. This way, the screw tightening was standardized with a seating force that did not considerably influence the vertical misfit gaps. It is important to stand out that this seating force $(5 \mathrm{~N} / \mathrm{cm})$ was used specifically for this in vitro investigation, and must not be used clinically.

In the present investigation, microscopic evaluation of the marginal misfit was employed. The measurements were taken by positioning the specimens on the microscope so that the marginal area of connection between the abutment and the implant could be observed from a directly perpendicular perspective. Other investigators ${ }^{10,14,15,21}$ have also used this methodology. This allows measurement of the marginal discrepancy in a non-destructive manner, with multiple readings of specimens. Even though there are several three-dimensional methods for evaluating prosthetic misfit, the sophisticated equipment required for such analyses are not promptly available ${ }^{10,12}$. Utilization of the most common techniques still provides information on the relative fit or misfit of prostheses, even though it is acknowledged that such techniques are not as precise as the three-dimensional methods ${ }^{10}$.

According to the currently available scientific-based evidences, despite the efficacy of contemporary dental technology employed in the fabrication of prosthetic frameworks, an absolutely passive fit cannot be achieved ${ }^{17}$. That is, the concepts of passivity provide necessary theoretical ideals, yet their achievement is impossible. The accomplishment of accurate clinical and laboratory procedures, combined with the use of rectifiers that may optimize the final outcomes, allow completion of rehabilitation with prostheses that will not impair the longevity of osseointegration.

\section{CONCLUSION}

The results of the present study allow the following conclusions: 1. Use of rectifiers in cast UCLA abutments reduced significantly the marginal misfit at the implantabutment interface; 2. Even with carefully performed laboratory steps, changes at implant interface of premachined UCLA abutments occurred; 3. Porcelain baking did not alter the marginal misfit values of UCLA abutments.

\section{ACKNOWLEDGMENTS}

To The São Paulo State Research Foundation (FAPESP), for granting a scholarship for development of this study (Process \# 04/05127-0). The equipment and materials used in this study were kindly supplied by the companies "Conexão Sistemas de Prótese" and "Wilcos". The study was conducted at the Dental School of São José dos Campos, São Paulo State University “Júlio de Mesquita Filho”, São José dos Campos, SP, Brazil. 


\section{REFERENCES}

1- Anusavice KJ, Carroll JE. Effect of incompatibility stress on the fit of metal ceramic crowns. J Dent Res. 1987;66(8):1341-5.

2- Burguete RL, Johns RB, King T, Patterson EA. Tightening characteristics for screwed joints in osseointegrated dental implants. J Prosthet Dent. 1994;71(6):592-9.

3- Byrne D, Houston F, Cleary R, Claffey N. The fit of cast and premachined implant abutments. J Prosthet Dent. 1998;80(2):18492.

4- Campbell SD, Pelletier LB. Thermal cycling distortion of metal ceramics: Part I- metal collar width. J Prosthet Dent. 1992;67(5):6038 .

5- Campbell SD, Sirakian A, Pelletier LB, Giordano RA. Effects of firing cycle and surface finishing on distortion of metal ceramic castings. J Prosthet Dent. 1995;74(5):476-81.

6- Carotenuto G, Palumbo M, Zarone F, Nicolais L. Characterization of the interface between prefabricated gold copings and cast dental alloy in implant restorations. Clin Oral Implants Res. 1999;10(2):1318 .

7- De Hoff PH, Anusavice KJ. Effect of metal design on marginal distortion of metal-ceramic crowns. J Dent Res. 1984;63(11):132731 .

8- Goossens IC, Herbst D. Evaluation of a new method to achieve optimal passivity of implant-supported superstructures. SADJ. 2003;58(7):279-85,287.

9- Guichet DL, Caputo AA, Choi H, Sorensen JA. Passivity of fit and marginal opening in screw or cement-retained implant fixed partial denture designs. Int J Oral Maxillofac Implants. 2000;15(2):239-46.

10- Hecker DM, Eckert SE. Cyclic loading of implant-supported prostheses: changes in component fit over time. J Prosthet Dent. 2003;89(4):346-51.

11- Hoyer SA, Stanford CM, Buranadham S, Fridrich T, Wagner J, Gratton D. Dynamic fatigue properties of the dental implant-abutment interface: joint opening in wide-diameter versus standard-diameter hex-type implants. J Prosthet Dent. 2001;85(6):599-607.

12- Jemt T, Book K. Prosthesis misfit and marginal bone loss in edentulous implant patients. Int J Oral Maxillofac Implants. 1996;11(5):620-5.

13- Jemt T, Lekholm U. Measurements of bone and framework deformations induced by misfit of implant superstructures: a pilot study in rabbits. Clin Oral Implants Res. 1998;9(4):272-80.

14- Keith SE, Miller BH, Woody RD, Higginbottom FL. Marginal discrepancy of screw-retained and cemented metal-ceramic crowns on implants abutments. Int J Oral Maxillofac Implants. 1999;14(3):369-78.

15- Koke U, Wolf A, Lenz P, Gilde H. In vitro investigation of marginal accuracy of implant-supported screw-retained partial dentures. J Oral Rehabil. 2004;31(5):477-82.

16-Lewis SG. Esthetic implant restorations. Compendium. 1994;15(3):334,336,338 passim; quiz 346.

17- Sahin S, Cehreli MC. The significance of passive framework fit in implant prosthodontics: current status. Implant Dent. 2001;10(2):85-92.
18- Smedberg JI, Nilner K, Rangert B, Svensson SA, Glantz PO. On the influence of superstructure connection on implant preload: a methodological and clinical study. Clin Oral Implants Res. 1996;7(1):55-63.

19- Vasconcellos DK, Cardoso AC, Bottino MA, Magini RS, Andriani W Jr. High temperature dimensional alterations of implant supported frameworks. Braz J Oral Sci. 2005;4(12):689-94.

20- Vigolo P, Majzoub Z, Cordioli G. Measurement of the dimensions and abutment rotational freedom of gold-machined 3i UCLA-type abutments in the as-received condition, after casting with a noble metal alloy and porcelain firing. J Prosthet Dent. 2000;84(5):54853.

21- Zervas PJ, Papazoglou E, Beck FM, Carr AB. Distortion of threeunit implant frameworks during casting, soldering, and simulated porcelain firings. J Prosthodont. 1999;8(3):171-9. 